Profesora de Posgrado en Comunicación en la Universidad Europea del Atlántico. Es candidata a Doctora en Filosofía por la Universidad de Barcelona en España. Máster Oficial en Antropología por la Universidad Autónoma de Barcelona, así como Máster en Dirección y Gestión de Proyectos de Cooperación Internacional. Licenciada en Periodismo por la Pontificia Universidad Católica de Minas Gerais, en Brasil.

Historial editorial Recepción: 23 de febrero de 2021 Revisión: 3 de marzo de 2021 Aceptación: 7 de mayo de 2021 Publicación: 28 de junio de 2021 


\title{
La imagen corporal como relación social: la representación del cuerpo en el retrato y el autorretrato
}

\author{
Body image as a social relationship: \\ the representation of the body in portraits \\ and self-portraits
}

\section{Imagem corporal como relação social: a representação do corpo em retratos e autorretratos}

\author{
Michelle Moreira Soares \\ Universidad Europea del Atlántico \\ micaes@hotmail.com
}

\section{Resumen}

El artículo analiza, desde una perspectiva antropológica, principalmente, y con contribuciones de la sociología y los estudios visuales, la presentación social del cuerpo a través de la fotografía, más concretamente nos indagamos sobre la relación que establece la persona con sus imágenes corporales, tanto en la producción como en la circulación de fotografías como objetos de sociabilidad. La incursión al tema se hace a partir de una breve reflexión sobre el concepto de imagen corporal, la revisión sobre la representación del cuerpo en la fotografía en diferentes ámbitos que nos sirven como marcadores culturales, y el enfoque sobre la presentación social del cuerpo en los procesos de interacción social. A través de entrevistas, se revelan percepciones sobre la imagen corporal en la fotografía y la circulación de estas imágenes en redes sociales, se describen algunas inquietudes sobre fotografiar y ser fotografiado en retratos y autorretratos, principalmente asociadas a modelos de representación, patrones de belleza y conflictos entre lo privado y lo público.

Palabras clave: Fotografía, Imagen corporal, Retrato, Autorretrato, Presentación social del cuerpo 


\section{Abstract}

The paper analyzes, from an anthropological perspective, and contributions from sociology and visual studies, the social presentation of the body through photography, more specifically we inquire about the relationship that the person establishes with their body images, both in the production and in the circulation of photographs as objects of sociability. The incursion into the subject is made from a brief reflection on the concept of body image, the review on the representation of the body in photography in different areas that serve as cultural markers, and the focus on the social presentation of the body in the social interaction processes. Through interviews, perceptions about body image in photography and the circulation of these images on social networks are revealed, some concerns about photographing and being photographed in portraits and self-portraits are described, mainly associated with representation models, beauty patterns and some conflicts between the private and the public.

\section{Keywords: Photography, Body Image, Portrait, Self-portrait, Social Presentation of the Body}

\section{RESUMO}

O artigo analisa, desde uma perspectiva antropológica, e contribuições da sociologia e dos estudos visuais, a apresentação social do corpo por meio da fotografia, mais especificamente indagamos sobre a relação que a pessoa estabelece com suas imagens corporais, tanto na produção quanto na circulação, das fotografias como objetos de sociabilidade. A incursão no assunto é feita a partir de uma breve reflexão sobre o conceito de imagem corporal, da revisão sobre a representação do corpo na fotografia em diferentes áreas que servem como marcadores culturais, e do enfoque na apresentação social do corpo nos processos de interação social. Por meio de entrevistas revelam-se percepções sobre a imagem corporal na fotografia e a circulação dessas imagens nas redes sociais, descrevem-se algumas preocupações em fotografar e ser fotografado em retratos e autorretratos, principalmente associadas a modelos de representação, padrões de beleza e alguns conflitos entre o privado e o público.

\section{Palavras-chave: Fotografia, Imagem Corporal, Retrato, Auto-retra- to, Apresentação Social do Corpo}


En el fondo la fotografía es subversiva, y no cuando asusta, trastorna o incluso estigmatiza, sino cuando es pensativa

Roland Barthes

El cuerpo es nuestra mayor referencia entre naturaleza y cultura. En él, experimentamos sensaciones fisiológicas como el dolor, la tensión o la relajación. Pero también construimos nuestra experiencia de vida corporal a partir de la experiencia social. Marcel Mauss fue uno de los primeros a afirmar que no hay nada de natural en la forma como utilizamos nuestro cuerpo. Nuestras posturas, como ejemplo, revelan un legado cultural. También están cargadas de herencias nuestras expresiones, movimientos, marcas y cuidados.

Este estudio se enmarca en lo que se define como presentación social del cuerpo, un ámbito de investigación antropológica que da relevancia al cuerpo como campo de construcción simbólica en las diferentes situaciones sociales de intercambio y relación.

Hablar de la presentación social del cuerpo significa tener muy en cuenta

el triángulo básico que podemos establecer entre el yo o identidad propia, el cuerpo y la sociedad, teniendo muy presente cómo se produce interactivamente el yo social mediante su presentación, es decir, mediante la performatividad. (Martí, 2010:108).

Aquí, esta performatividad está representada en la fotografía, no solamente como imagen, objeto de comunicación social. Sino más bien la fotografía como un proceso simbólico de participación e identidad en el marco de una sociedad occidental marcada por el visual, en que ver y ser visto se configuran acciones importantes para las relaciones sociales. Como afirma Mirzoeff, la cultura visual depende de esta tendencia moderna de vivenciar el mundo a través de las imágenes. (Mirzoeff, 2003:23).

Dado que lo visible puede ser concebido como un campo de inscripción y proyección de acción social (Brighenti, 2010: 4), la idea de visibilidad constituye un útil conceptual más para ayudarnos a entender los complejos procesos de interacción que configuran el ámbito social, y muy especialmente por lo que concierne a la presentación social del cuerpo. (Martí, 2013:50).

Consideramos que, más que representar el cuerpo, la imagen corporal fotografiada representa una reconstrucción continua del vivir socialmente. Además de indicar la estructura social, la fotografía también ha sido históricamente estructurante para la construcción de la imagen corporal, su representación y presentación social.

La práctica fotográfica, analizada aquí, supone la elaboración de significados enclavados en la representación del cuerpo a través del retrato o del autorretrato al compartirlos en las redes sociales. Esta 
representación expone la combinación entre la imagen corporal individual con una herencia icónica culturalmente común, a partir de la identificación de referencias visuales propias de un estilo o de un contexto.

Como reflexión antropológica, el estudio de la práctica fotográfica como medio de presentación social del cuerpo nos permite analizar algunos factores que influencian para las percepciones individuales en un contexto cada vez más dominado por imágenes.

En este sentido, la fotografía resulta ser producto cultural de una sociedad marcada por la producción, el consumo y la tecnología que habilitan un sistema específico de sociabilidad y visibilidad. Diversos autores han contribuido para pensar la fotografía por sus funciones sociales, como Susan Sontag, Pierre Bourdieu, John Tagg, entre otros. En estos estudios, la representación es fundamental para la comprensión de la fotografía como medio social.

Como plataforma de interacción en este sistema, la fotografía va permitir la reconstrucción de la imagen corporal para su uso como medio de presentación. En Goffman, una referencia teórica importante en los estudios de antropología y cuerpo, este uso se simula teatralmente, en su obra publicada originalmente en 1959, La presentación de la persona en la vida cotidiana. De manera similar, aquí analizaremos la relación que se construye uno con su imagen fotografiada en interacción social desde esta metáfora de escenificación.

Como punto de partida, a partir de entrevistas cualitativas se propone una reflexión sobre la temática en conjunto con un análisis de los usos sociales de la fotografía, en el contexto ya citado.

\section{LA REPRESENTACIÓN FOTOGRÁFICA}

La fotografía tiene como definición clásica 'el registro de la luz sobre un material sensible a ella'. Sin embargo, esta categorización falla en diversos aspectos. Si tenemos en cuenta los efectos de la luz solar sobre los elementos presentes en la naturaleza, la fotografía representaría fenómenos diarios tan simples como la marca del sol en la piel, la pérdida de color de una ropa expuesta al sol o las transformaciones físicas que ocurren en las hojas de las plantas, variables por la luz. A estos fenómenos no consideramos exactamente como fotografías (Machado, 2002).

Primeramente, para ser una fotografía, se exige cierta producción técnica e interferencia humana a partir de mecanismos ópticos, químicos o eléctricos, o elecciones estéticas como encuadramiento, 
enfoque, controle de entrada de luz y movimiento, uso de filtros y otros. La realización de esta producción técnica no es resultado de un acto deliberado, exige una intención, es decir, el deseo de fotografiar.

En segundo lugar, la mecanización en la fotografía, a partir de los recursos y técnicas relacionados, posibilita que la práctica sea instrumento de control y poder. La exigencia por el conocimiento técnico y estético, la posesión del objeto máquina que permite la formación de la imagen, la apropiación de los espacios de difusión públicos de las fotografías son factores que demandan determinado dominio sobre los medios de producción y visibilidad. Cada época dispone de una técnica que implica determinado comportamiento de quien toma la foto o de quien es fotografiado. Para una toma fotográfica realizada durante el siglo xIX era necesario más conocimiento de elementos químicos y físicos, distinto de lo que se exige hoy con las cámaras en móviles y dispositivos tecnológicos. En términos generales, el desarrollo de la técnica, su difusión comercial y accesibilidad de consumo han permitido a todos participar en mayor grado de la producción de imágenes.

En la práctica de fotografiar retratos y autorretratos se ve evidencias de la lógica social de la fotografía como instrumento de poder. La idea ha sido bastante desarrollada por teóricos como Foucault y Bourdieu, que analizaron los sistemas simbólicos presentes en la práctica fotográfica que posibilitan determinado estatus social. Así como afirma Pultz, "toda una serie de relaciones dentro del proceso fotográfico - cámara a objeto, lente a película, observador a fotografíareproduce la posición de un sujeto ilustrado, privilegiado y único: el observador aparte que contempla libremente algún objeto o escena”. (Pultz, 2003: 9)

Sin embargo, además de estas exigencias técnicas que marcan su carácter mecánico y productivo, la concepción simplista de que fotografiar es apretar un botón, idea popularmente difundida, ha delegado a segundo plan acciones esenciales de la toma fotográfica como son la elección del tema, la creación de la toma y la edición a partir de la selección de un conjunto de imágenes publicables. Más que 'congelar un momento' a partir de una técnica, el proceso fotográfico se constituye de acciones más variadas como son el ver-pensar-interpretar-crear-difundir-comunicar-relacionar, que conllevan en sí un conjunto de referencias previas de un legado iconográfico común.

Así que, entre la producción técnica y la elección estética, hay un trasfondo inevitablemente cultural que es lo que permite la construcción de significados y conceptos en una imagen fotográfica. Según Bourdieu: 
(...) aun cuando la producción de la imagen sea enteramente adjudicada al automatismo de la máquina, su toma sigue dependiendo de una elección que involucra valores estéticos y éticos: si, de manera abstracta, la naturaleza y los progresos de la técnica fotográfica hacen que todas las cosas sean objetivamente "fotografiables", de hecho, de la infinidad teórica de las fotografías técnicamente posibles, cada grupo selecciona una gama finita y definida de sujetos, géneros y composiciones. (Bourdieu, 2003:43)

A partir de un mayor acceso a la cámara fotográfica y la difusión de imágenes a través de las redes sociales, la fotografía ha colaborado para difundir prácticas de consumismo como son el turismo o la moda. Pero principalmente, ha sido herramienta fundamental para la elaboración y comunicación de valores culturales referentes al cuerpo.

Ahora bien, para comprender el vínculo que la fotografía ha tenido con el corpóreo, antes hay que revisitar algunas de las influencias históricas de su práctica que han colaborado para el imaginario visual sobre el cuerpo en la fotografía.

\section{LA FOTOGRAFÍA Y EL CUERPO, REPRESENTACIONES}

Al enseñarnos un nuevo código visual, las fotografías alteran y amplian nuestras nociones de lo que es digno de mirar y lo que tenemos derecho a observar. Son una gramática y aún más importante, una ética de ver. Finalmente, el resultado más grandioso de la empresa fotográfica es darnos la sensación de que podemos tener todo el mundo en nuestra cabeza, como una antología de imágenes. Susan Sontag, Sobre la Fotografía

En la iconografía, el cuerpo humano ha sido el principal protagonista de las representaciones fotográficas. Desde diferentes usos sociales, la práctica ha permitido la construcción de una colección icónica sobre el cuerpo dando continuidad a la herencia pictórica propia de las sociedades cristianas.

John Pultz (2003) elaboró diferentes ejemplos para ilustrar el uso de la fotografía como instrumento de control ideológico del cuerpo. Utilizadas desde comienzos del siglo XIX, las fotografías han servido para reafirmar la manipulación de estereotipos a partir de su uso en campos científicos tan diversos como son la antropología, la psiquiatría, la medicina y la fisiología.

Debido a su falso carácter realista, la fotografía ha sido confundida como documento, como archivo histórico, permitiendo su uso como medio de información y conocimiento, instrumento de apoyo a la investigación científica y evidencia objetiva de la realidad. Como ya 
lo abordó diversos autores como Ribalta, Pinney, Edwards, la fotografía conlleva el discurso como lenguaje universal capaz de comunicar y difundir la ideología del positivismo, propia del Estado liberal, industrial y colonial.

En la antropología, inicialmente la fotografía ha servido para sistematizar el dominio del colonialismo sobre los pueblos conquistados, a partir de imágenes de cuerpos desnudos, medidos y estudiados como objetos científicos (Moreira, 2021). Las fotografías revelan personas sin personalidad propia, sino signos de una cultura lejana y extraña. Integrantes de comunidades indígenas, aborígenes, africanas y orientales fueron fotografiados como íconos del exótico mundo no-europeo, personajes de crónicas culturales y de la construcción del "otro", del diferente. Esta práctica ha colaborado para construir un imaginario anacrónico sobre la idea de razas.

De la manera similar en las Ciencias Sociales, los estudios de tipos humanos marginalizados utilizaron la fotografía del cuerpo como registro fisionómico de las diferencias de conducta social, en gran parte estereotipada por su entorno social. La estructura policial utilizó la fotografía para demarcar rostros: carteles de criminales, las fotografías de encarcelados y de investigaciones policiales han utilizado el cuerpo para reforzar el sistema penal y punitivo.

En la década de 80, el uso científico de la fotografía sufrió críticas a partir de la crisis de representación propia del postmodernismo. En este momento, la atención se centró más en la interpretación de los códigos simbólicos presentes en la representación y en sus efectos. La fotografía comparte con la antropología sus dudas: ¿quién habla y cómo influye en el discurso? ¿Cómo se lleva a cabo la representación del observado por parte del observador?

(...) superar el paradigma positivista de la realidad empírica y pasar a un enfoque constructivista y de selección visual de la realidad ha supuesto apostar por la continuidad entre sujeto y objeto y la discontinuidad entre lo real y la apariencia, la autenticidad, la autoridad y la autoría, y, frente a la precisión de la versión única, incorporar la ambivalencia y la ambigüedad de las versiones múltiples. (Buxó,1999:5).

Como consecuencia, una nueva tendencia se instaura como práctica: el estudio de la autorepresentación. Algunas investigaciones se preocupan en analizar las representaciones realizadas por los propios grupos culturales sobre sí mismos, hecho que posibilita mayor empoderamiento sobre la representación de la propia imagen corporal. La práctica es facilitada por el acceso más fácil a dispositivos fotográficos con el avance tecnológico de los años 90 y 2000. 
Ya en el campo artístico, la fotografía también ha estado sujeta a fuerzas ideológicas. "Durante la segunda mitad del siglo XIX, aparte de su uso como medio para definir el cuerpo humano en términos de clase y conducta normativa, la fotografía se utilizaría para crear el cuerpo erótico y sexualmente diferenciado". (Pultz, 2003:37). Entre las fotografías artísticas, la sexualidad ha marcado la representación del cuerpo y la diferenciación de género en el siglo XIX, hasta mediados del siglo pasado. La representación de roles femeninos en la historia de la fotografía y arte pictórica ha explorado estereotipos femeninos como son la mujer desnuda y sensual, la maternidad y la mujer en el ámbito doméstico o la inocencia juvenil. En las representaciones masculinas, no era común encontrar el cuerpo erótico, que empieza a aparecer de manera más corriente a partir de la segunda mitad del siglo pasado con representaciones más habituales de hombres desnudos. Las fotografías coinciden con la difusión y apertura social a homosexualidad, a partir del trabajo de artistas que cuestionan las formas de representación de género.

Con la predominancia de fotógrafos hombres, las mujeres han tenido menos papel en la representación del cuerpo. Aun así, en el arte, algunas artistas han trabajado con sus propios cuerpos como reivindicación al tema de la representación corporal femenina. Un antecedente a lo que hoy es una tendencia, estas artistas se fotografiaban fuera de los contextos habituales, representadas en autorretratos como alternativas del discurso dominante.

En el campo de las comunicaciones, amplio e influyente medio de significación social, el fotoperiodismo y la fotografía documental nos han brindado un imaginario visual compuesto por cuerpos violentados, víctimas de guerra, desastres naturales, violencia urbana, miseria social y hambre. Delante de las crónicas visuales periodísticas, vemos la fragilidad física y moral de la sociedad a través del sufrimiento y desfiguración del cuerpo.

Por otro lado, los valores añadidos a las imágenes de deportistas, políticos, artistas ("personalidades") configuran un referencial de apariencia, principalmente relacionados a los modos de vestir y peinarse. La construcción del cuerpo en el fotoperiodismo, y su saturación, ofrece un marco de diferenciación entre lo común y lo espectacular a través de modelos exaltados o recusados socialmente. La fotografía contribuye para estas narrativas al crear en el imaginario una iconografía de referencia, tal como afirma Flusser, "fotografías pueden ser considerada modelos”. (Flusser, s.f.). sea para el conocimiento, para la vivencia o para el comportamiento. Como modelo de comportamiento, la fotografía incide sobre nuestra percepción con finalidades políticas, o bien, propagandísticas en sentido amplio. 
En el marco de la presentación social del cuerpo, es fundamental comprender todo este bagaje visual que la cultura fotográfica ha forjado en las construcciones de la imagen corporal. Con la publicidad y los medios de comunicación de masa, la influencia que representaciones tienen sobre el cuerpo ha sido aún mayor, produciendo efectos en los más diferentes grupos culturales. La moda y el consumo han sido los principales instrumentos para la significación de las marcas como tótems de una sociedad de la apariencia, elementos claves para la fachada (en el sentido de Goffman). Además, la pose, elaborada por modelos para campañas publicitarias, se transforman en un elemento cultural del lenguaje corporal; utilizable como aportación simbólica en las relaciones sociales.

Jean Baudrillard comentó sobre esta lógica social del consumo, en que el cuerpo aparece como objeto diferenciado que proporciona la posibilidad de salvación a partir de la inversión y significación. Por un lado, es capital, por otro, es fetiche. (Baudrillard, 1970:185213). También Patrizia Calefato (2001) analizó la cuestión de la moda sobre la condición de estar y ser en el mundo, y su estilo de apariencia. Ella cuestiona hasta qué punto el cuerpo se percibe a través de tipos ya vistos y sentidos.

En la esfera más doméstica, Bourdieu nos ha enseñado a partir de la investigación realizada en la década de 60 , cómo la fotografía ha servido como instrumento de mediación para solemnizar la familia. El nacimiento de un nuevo integrante, la boda, el bautizo y las reuniones familiares son temáticas constantes en las fotografías de retrato que se realizan en el interior de los hogares franceses como recurso para reforzar los vínculos familiares y registrar la existencia y la pertenencia a un grupo. A cierto modo, no sería inocente afirmar que la práctica se extiende también a otros lugares de la sociedad moderna occidental, visible en las producciones de los álbumes fotográficos familiares.

La fotografía de familia enmarca el cuerpo individual en su contexto más identitario: la familia nuclear, el clan o el grupo al cual el individuo pertenece y posibilita una construcción de la memoria al solemnizar los cambios corporales. La práctica fortalece la propia institución familiar al marcar y difundir su existencia a través de los álbumes, marcos sobre mesas y en las paredes, o en una práctica más extendida actualmente, a través de envíos de fotografías a otros parientes o amigos.

En el mismo estudio, Bourdieu resalta la fotografía como recurso de diferenciación social que representa las estructuras económicas a través de las imágenes de turismo realizadas en los viajes vacacionales. El poder de consumo es entonces registrado y divulgado como un diferencial del status social. 
Hasta este punto, hemos intentado de manera breve comprender algunos de los usos de la fotografía para la creación de modelos de representación y usos sociales vinculados al cuerpo. Nos faltaría investigar más a fondo la antología de imágenes fotográficas de lo corpóreo ya producida culturalmente, pero la tarea se hace compleja por la heterogeneidad de categorizaciones que han marcado, en los campos ya citados, nuestro imaginario visual sobre el cuerpo.

\section{IMAGEN CORPORAL EN LA RELACIÓN SOCIAL: YO PRESENTO MI REPRESENTACIÓN}

La fotografía del cuerpo tiene cada vez más espacio como objeto de intercambio simbólico en las sociedades complejas donde las redes sociales son mediadas por dispositivos electrónicos. A través del envío de fotografías a una persona o a un grupo o su exhibición en una página de Internet, presentamos nuestra imagen de cuerpo como partícipe de las normas de conducta social. En este intercambio de imágenes reproducimos, a través del lenguaje corporal, las referencias culturales que hemos tenido a partir del arte, de los medios de comunicación, de la ciencia y de normas propias de cada grupo cultural. Es capital comprender de qué manera estas referencias inciden como estrategias de control y disciplina para la construcción de la imagen corporal en diferentes sentidos como pueden ser la belleza, la participación social o la sexualidad.

Como elemento de presentación social, la fotografía posibilita la objetivación de la representación de la persona con base en lo que aquí entendemos como "imagen corporal”. La 'imagen corporal' puede ser entendida como la percepción visual consciente que uno tiene de su cuerpo, desde el punto de vista de Schilder: "La imagen del cuerpo es la figura de nuestro propio cuerpo que formamos en nuestra mente, es decir, la forma en la cual nuestro cuerpo se nos representa a nosotros mismos". (Schilder, 1983:252).

Sin embargo, la definición de Schilder es limitada por su perspectiva puramente psíquica, vivida a partir de la experiencia del cuerpo, sin contemplar la influencia cultural. Mary Douglas (2003b:166) nos dice que la imagen corporal que construimos resulta una fotocopia de la estructura social que vivimos. De manera complementar, dicha imagen también puede ser elaborada para transgredir esta misma estructura, actuando como un acto de desorden social. En este sentido, muchas de las imágenes pueden ser entendidas como construcciones intencionales de manifiesto o crítica. 
Nos interesa particularmente la idea de Goffman, donde la imagen corporal se transforma en una puesta en escena a partir de la interacción con el otro: "la fachada (front) parte de la actuación del individuo que funciona regularmente de un modo general y prefijado, a fin de definir la situación con respecto a aquellos que observan dicha actuación”. (Goffman, 2006: 34). Para Goffman, las personas intentan ser convincentes en los roles a partir de la interiorización de reglas corporales como son el vestir y la postura, visibles en la apariencia y los modales, para participar de los diferentes tipos de encuentros sociales que contienen pautas específicas de conducta. En su teoría, vivimos una escenificación continua en las interacciones sociales.

Aguado, en su definición, relaciona la imagen corporal a la idea de identificación cultural.

La imagen corporal es, en definitiva, la estructura simbólica en la que la cultura recrea los mensajes centrales para que el sujeto pertenezca. En este enfoque, entendemos el cuerpo humano como el primer espacio-tiempo, ya que dicha red se construye a partir de la significación del propio cuerpo. (Aguado, 2004:49).

En el sentido de Aguado, la imagen corporal tiene una relación profunda con la identidad ya que se refiere al reconocimiento de Yo frente al Otro a través del cuerpo.

La imagen corporal es, desde la perspectiva ideológica, la institución de la identidad. Es a la vez medio y fin de la cultura, sujeto y objeto privilegiado en el proceso recíproco a través del cual los individuos se incorporan a la cultura y la cultura pasa a formar parte integrante del sujeto. (Aguado, 2004:32).

\section{RETRATO}

El concepto de retrato está estrechamente relacionado con los conceptos de identidad y alteridad que marcan el estar en el mundo y su entorno cultural. Actualmente, el retrato fotográfico elucida el deseo de participación social a partir de su difusión en las redes sociales, "es como si fuera la respuesta a la necesidad de protagonismo del retratado y del retratista”. (Casajús, 2009:238).

En la producción del retrato, el fotógrafo tiene el poder de elegir la estética de la representación, y al fotografiado construir la pose. Hay por tanto un doble juego a la hora de producir significados. Sin embargo, al momento de seleccionar la imagen y hacerla pública, de manera más común es el fotógrafo quien tiene la decisión definitiva.

El retrato se ha extendido desde la pintura como medio de representación del cuerpo principalmente por su capacidad de apro- 
ximación ya que, a través del rostro, de las manos o de la postura corporal podemos identificar sentimientos. La expresividad se ofrece a partir del lenguaje corporal, fotografiable en los retratos a partir de los gestos, trazos y expresiones faciales y modos de vestir.

A partir de entrevistas, buscamos revisar la percepción de adultos, con edad entre 30 y 40 años, como incursión al campo de los sentidos de la práctica del retrato.

\section{LA PRODUCCIÓN DE RETRATOS}

Nuria revela su interés en la expresión humana, esta expresión se desvela en el lenguaje corporal. "Me gusta hacer fotos de personas, retrato, porque las personas tienen más expresión. Cuando viajo, me gusta fotografiar gente", afirma. María, por otro lado, afirma: "me gusta hacer fotografías de retrato porque creo que tienen más intimidad por enseñar las sutilezas de una persona”. Esta afirmación nos remete a una idea popularizada de que algunas personas, especialmente pueblos indígenas, tienen de que fotografiar es robar el alma de la persona, como si al hacerle una fotografía estuviera revelando su «íntimo».

A Cristina afirma que no le gusta hacer fotografías de personas porque considera "invasivo":

Cristina: A veces hago retrato, de personas próximas a mí. Sólo hago fotos de personas que yo conozco, no hago foto de personas desconocidas porque creo que puede ser un poco invasivo, me quedo preocupada con lo que las personas pueden pensar si hago fotos suyas.

Para las dos entrevistadas, encontramos que la fotografía de retrato se asocia a intimidad e invasión, como se la imagen corporal de la persona fotografiada estuviera asociada a un elemento más sagrado e impeditivo. Sin embargo, esto se refiere a la relación dicotómica entre privado y público de la imagen corporal y la construcción de identidad social. Es interesante conectar esta sensación de invasión con una preocupación que concierne a la sociedad actual: la privacidad y el control de lo que se denomina derecho de imagen. El derecho de imagen, constituido jurídicamente, existe para proteger esta supuesta “identidad" revelada en la imagen corporal exhibida. El derecho de imagen se organiza de manera emblemática para el uso de la imagen corporal como elemento de identidad, y garantiza el control del sujeto fotografiado sobre el uso de su fachada (Goffman) cuando así sea pertinente.

Otro entrevistado, Julio, nos comenta que no hace muchas fotografías de personas, pero le gusta tener los momentos con amigos 
registrados. "Cuando hago algún retrato, me gusta fotografiar el rostro. Así puedo ver su cara de cerca. Hago con la cámara del móvil, de la manera más práctica y rápida, la verdad”.

Carmen: No me gusta fotografiar retratos, porque veo muchos defectos de las personas. Me gusta enseñar las personas y el paisaje junto para retratar dónde estaba. Cuando hago es porque quiero registrar las personas que están conmigo o han participado de algo conmigo.

María más adelante afirma: "me gusta más las fotografías espontáneas que las con pose. Las fotografías con pose son muy obvias, y se quedan iguales". Ella se percibe como observadora y admite: "prefiero realizar la fotografía sin que la persona mire a la cámara». Sin embargo, realiza una gran cantidad de imágenes para elegir una foto. "Yo soy un poco japonesa. Hago fotos de arriba, de espaldas, adelante. Plano americano, pongo de lado, hago varias. Así hago unas diez para conseguir una buena. Me gusta hacer varias para tener una que me guste”.

Nuria, como María, no le gusta hacer retratos con pose:

Pido a las personas antes de realizar la foto, prefiero pedir. Considero invasivo hacer una foto sin pedir. El problema es que cuando pido, normalmente, pierdo el momento más bonito. La persona cambia la postura y pasa a posar para la foto. Me gusta capturar la historia, y cuando pido a la persona, yo oriento que no mire a la cámara, no ponga la mano en la cintura. Creo que lo bonito en la fotografía de personas es coger el momento.

Por los testimonios, como hemos visto se percibe un interés por encontrar esta «esencia» de una persona: su intimidad. Sin embargo, esta expresividad del íntimo tal como afirman debe estar contextualizada en un momento, no en una pose, mismo que haga falta simular el momento o fingirlo. Hay una contradicción evidente en las afirmaciones, ya que la pose debería indicar el lenguaje corporal expresivo que dicen buscar. Al contrario, según señalan, las personas hacen poses obvias. El obvio a que se refieren debe estar relacionado a una herencia icónica en el imaginario colectivo que influencia a la hora de la pose repitiendo formas ya vistas.

Como establece Barthes "[...] lo que fundamenta la naturaleza de la Fotografía es la pose”. (Barthes, 1989:122). A los principios de la fotografía, para llenar la necesidad que los clientes tenían por sus fotografías y delante de las dificultades técnicas que exigían largos tiempos para la cámara poder registrar el modelo, ha sido la pose la única técnica posible para garantizar la calidad del retrato. Para esto, se desarrollaron aparatos específicos para apoyar el cuerpo y la cabeza. La rigidez del cuerpo marcó una forma de representación para quién es fotografiado, bien que, a día de hoy, mismo con el desarrollo de 
esta tecnología, las personas siguen "haciéndose de estatuas" cuando alguien les hace una fotografía. La referencia a la transformación del cuerpo físico a cuerpo simbólico (Barthes), es decir, la objetivación del registro está representada en el acto de posar.

Por otro lado, el "momento" a que se refiere Nuria, y la "historia”, como afirma María, se conforman como un elemento fundamental para la producción de significado en la fotografía de retrato: indica la actuación del rol de la persona fotografiada. Así como ocurre en la interacción social descrita por Goffman, la actuación permite ver el ritual y apariencia que cada uno desarrolla a partir de un ambiente específico. Al contrario de una fotografía posada, que podría revelar la imagen corporal como metáfora social, al realizar la foto, las entrevistadas esperan recriar el ambiente de interacción social como se fueran meras espectadoras del real.

Pero Nuria asevera que, si es necesario, dirige los fotografiados a que simulen este momento "espontáneo". "Cuando pido una persona para hacerle una foto, le digo para no posar. Mira para allá, coge el móvil, finge que está haciendo algo. [...] Yo siempre intento hacer la foto fingiendo que no esté posando". Si la fotografía de pose es un fingimiento, la simulación a no-pose es lo que Baudrillard ha denominado simulacro. Esta hiperrealidad presenta una vivencia más atractiva y seductora.

\section{SUJETO FRENTE A SU PROPIA IMAGEN CORPORAL FOTOGRAFIADA}

cuando me siento observado por el objetivo, todo cambia: me constituyo en el acto de "posar", me fabrico instantáneamente otro cuerpo, me transformo por adelantado en imagen

Roland Barthes

Cuestionados sobre la sensación de ser fotografiados, es interesante ver cómo se configuran incertezas e incomodidad entre las respuestas.

María: Empiezo a imaginar cómo va a salir la foto, o sea, siempre paso por este punto, de preguntarme cómo será la foto. ¿Cómo me voy a sentir cuando me vea en la foto? Siempre paso por ahí, pero normalmente cuando es el otro, yo pienso... ah, que importa... porque no parto de la decisión, quien decide es el otro, pero si soy yo quien voy fotografiar, puedo desistir. Pero cuando es el otro, no puedo hacer mucha cosa.

La cuestión del poder está claramente implícita en el juego de la fotografía: quien tiene la cámara tiene el poder de decisión, de la mirada y de la posibilidad de control de la imagen del fotografiado. Esto podría provocar una inseguridad pero que no indica, aparente- 
mente, resistencia; al contrario, se acepta que el otro pueda decidir esta construcción de la imagen ya que es quien porta la cámara, es decir, el narrador visual. María no cuestiona aquí su posibilidad de interferir y elegir como persona fotografiada, sujeto también integrante de la narrativa.

Cristina dice preferir ser fotografiada sin que lo sepa, para no tener que posar:

No soy una persona tímida, pero parece un punto de timidez. No me siento totalmente cómoda, independiente de quién hace la foto. Cuando alguien va a ser una foto mía no consigo hacer con naturalidad, no sé cómo ponerme. ¿Sabe aquella espera antes de hacer la foto? Ella está preparando la foto y tú estás esperando como una estatua a ser fotografiada, yo creo que esta espera es muy mala. Por esto es mejor cuando alguien hace una foto de ti sin que lo sepas, porque además de la persona capturar la naturalidad, no tienes por qué estar posando.

Mario: Siento un poco de vergüenza, porque no sé cómo posar. No sé posar y entonces no sé cómo actuar, en general hago bromas. Pero la verdad, es que no me gusta cómo salgo en las fotos, creo que siempre salgo peor en la imagen que en la realidad soy.

Una vez más encontramos la cuestión de la pose como un elemento incómodo entre las fotografías de retrato, en este caso la persona fotografiada no sabe cómo ponerse: qué imagen corporal debería pasar para la cámara.

Sobre la falta de identificación con la propia imagen, Barthes expone sobre su deseo de realizar una imagen propia más próxima de cómo es "íntimamente": "móvil, sometida al traqueteo de mil fotos cambiantes, a merced de las situaciones, de las edades, coincida siempre con mi "yo" (profundo, como es sabido)" (Barthes, 1989: 42). Reconoce entonces el por qué del sentimiento de contrariedad concluyendo que "es la imagen la que es pesada, inmóvil, obstinada (es la causa por la que la sociedad se apoya en ella), y soy yo quien soy ligero, dividido, disperso [...]" (Barthes, 1989, 43)

Julio dice que cuando le hacen una foto siempre si pregunta dónde saldrá la fotografía, "me interesa mantener mi privacidad". Encontramos una vez más, la privacidad relacionada a la imagen corporal fotografiada. Pero, Julio, en general, no se siente incómodo cuando le hacen una fotografía, al contrario, afirma que sonríe para demostrar simpatía y que está de acuerdo con la toma fotográfica. La sonrisa se configura entonces como instrumento de interacción y empatía, y el cuerpo se manifiesta como partícipe de la puesta en escena.

Carmen: Odio cuando me hacen una foto porque sólo veo mis defectos, no me gusta para nada. La fotografía tiene esta característica: enseñar defectos que en el espejo no lo ves. En la foto, veo la realidad. Mirando al espejo me veo más guapa que en una fotografía. 


\section{El autorretrato}

El autorretrato es un formato proveniente del arte, especialmente del arte pictórico. Pero ha sido usado socialmente como herramienta de empoderamiento, participación, experimentación y autoconocimiento. Las tecnologías de comunicación han favorecido este formato, con dos cambios añadidos: el selfie y el palo selfie. El selfie tiene una connotación aún más personal por limitar el autorretrato a la fotografía realizada con la cámara en la mano. La técnica resulta en fotos con rostros próximos y a una distancia corta que posibilita la práctica sin mucha elaboración o planeamiento.

El selfie es la expansión de la fotografía como práctica de consumo, y ha permitido el registro diario de la imagen corporal. La creación del mercado del palo selfie como prolongación del brazo, una herramienta inventada para mejorar la imagen resultante del selfie, provoca algunos debates sobre los temas de la autoafirmación e individualidad. Cuestionados, ninguno de los entrevistados afirmó tener el palo selfie, y a principio rechazaron su intención de tenerlo. Dos de los entrevistados afirmaron tener vergüenza de usarlo.

La fotografía selfie se diferencia del autorretrato por la técnica productiva utilizada al hacer la imagen. Como toda técnica conlleva en sí un modo de representación, la práctica de selfie ha alterado también la percepción de la imagen corporal al producir como resultados, imágenes con ángulos distintos de un autorretrato estándar, creando un rostro sin proporción real. Las respuestas analizadas aquí se refieren al autorretrato sin distinción técnica, pero mayoritariamente se tratan de los selfies como práctica común.

Julio dice que no le gusta hacer selfies porque "ya no es original, se ha convertido en una cosa muy típica, casi kitsch. Cuando hago un autorretrato es con algún amigo o familiar, para demostrar un momento juntos, pero no hago a menudo".

En este comentario, la crítica al kitsch nos recuerda lo que Edgard Morin rescata de Rosenberg: "uno de los aspectos de la cultura de masa es la crítica kitschista del kitsch". (Rosenberg citado en Morin p. 26).

Mario dice que no hace fotografías de sí mismo, a no ser que sea para un trámite legal, una foto para un documento. «Porque mi imagen la veo cada día en el espejo y no siento necesidad de fotografiarme, es decir, no veo mi fotografía como algo artístico o de entretenimiento». Para Mario, la práctica de fotografiar es un evento que no está relacionado a su rutina personal, sino un ritual social para marcar encuentros familiares o entre amigos. 
María tampoco hace muchos autorretratos porque no se siente bien en las fotografías que realiza. «No me gusta hacer fotos mías, no me veo bien en las fotos. Muchas veces es frustrante porque todo mundo quiere salir bien en las fotos, ¿̇no?»

“Salir bien” en las fotos está también relacionado a un patrón de belleza:

María: creo que quizás sea una auto-exigencia mía, algún concepto que ni hace parte de mí. Este concepto de belleza, de salir bien, puede ni ser mío. Pero para evitar esta sensación, muchas veces no hago la foto. Prefiero hacer fotos de otras personas porque no tengo esta mirada crítica en relación a ellos.

Para María, la belleza es un marco de referencia para que le guste su propia imagen corporal en la fotografía. Esta belleza, como ella mismo dice, viene de algún preconcepto, es decir, se configura como un aspecto cultural para la elaboración de su autorretrato. Así también para Carmen: "He intentado hacer fotos selfies, pero no me gusta cómo salgo. No las divulgué para nadie”.

Es evidente que los modelos de representación generan ideales y tendencias que definen un marco de belleza y consecuentemente provocan la sensación de insatisfacción en relación con el propio cuerpo, lo que María llama de "frustrante". La comparación de la propia imagen corporal en la fotografía con estos modelos sirve para demarcar lo visible, o no visible, en la práctica de autorretrato.

$\mathrm{Si}$, por un lado, el desarrollo de la técnica y su acceso como bien de consumo extendido a casi toda la sociedad han permitido el empoderamiento de personas que ahora pueden elaborar la imagen fotografiada de su cuerpo como medio de presentación social, por otro, los modelos de representación difundidos que estructuran los conceptos de belleza o bien estar actúan como censura para el autorretrato. Una contradicción que puede anular, a depender del grupo social y su contexto de interacción, la producción y categorizar la visibilidad entre lo que es permitido o no enseñarse.

De la misma manera, el retoque de la imagen permitido hoy por medio de filtros y otras herramientas tecnológicas de edición ofrecen un amplio abanico de opciones para la reelaboración del autorretrato, y son utilizados para transformar la representación de la imagen corporal a partir de los patrones de belleza para su presentación social. La edición del autorretrato funciona, así como mecanismo de regulación de sí mismo para la mirada del otro. Un ejemplo que se puede ver en el testimonio de Nuria que domina estas técnicas de retoque, al revelar cierto sentimiento de confronto interior asumiendo que había retocado excesivamente sus imágenes. 
Nuria: "Antes yo retocaba mucho las fotos: retiraba las ojeras, las manchas de la piel. Algunas fotos son artificiales, pensé: menos edición. No hace falta hacer plástica. Yo siempre he sido contra la plástica. Ahora cada vez estoy dejando más natural. Antes yo hacía mucho más, no sé si estoy cada vez más aceptando como soy o si estaba quedando muy artificial”.

"Aceptar como es" se revela fundamental en la construcción de la imagen corporal y revela la inquietud que se vive con el propio cuerpo en la sociedad del espectáculo y simulacro, donde la apariencia es un valor significativo en las relaciones sociales y está referenciado por modelos de representación foráneos, en las palabras de Nuria, "artificiales”. Está clara la referencia a la industria cultural y su habilidad de crear modelos burocráticos e industriales de representación, donde el poder de creación muchas veces se limita en copiar referencias aceptadas y a utilizar técnicas propias de la cultura de masas (Morin, ). La presentación social del cuerpo a través del retrato se espeja en este espectro limitado dictado por esta industria cultural.

\section{LA EXHIBICIÓN EN LAS REDES SOCIALES}

Crear una fotografía del cuerpo, a través del retrato o autorretrato, y exhibirla públicamente, posibilita una representación de la imagen corporal elegida y objetivada en un acto de performance. Como hemos visto, a través de la representación de la imagen corporal, construimos una idea figurada de nosotros y de los otros, y demarcamos las diferencias entre identidad y alteridad.

El sujeto pasa a ser observado a través de la comunicación continua en los medios de comunicación virtuales como son las redes sociales o las mensajerías electrónicas (Whatsapp) que favorecen la interacción social por medio del intercambio de fotografías. La corporeidad se transforma precisamente en un signo virtual sin cuerpo. La práctica conlleva en sí un dilema para el sujeto que no sabe si prefiere participar de la red como protagonista o si prefiere mantener su privacidad y ausencia. La difícil elección está enmarcada en una sociedad que tiene como características la vigilancia y el espectáculo (Le Breton).

Las redes sociales permiten la recreación de las interacciones sociales por medio de la visibilidad y del simulacro. Como dice Sibilia sobre palabras de Guy Debord: "el espectáculo no es un conjunto de imágenes, sino una relación social entre personas mediada por imágenes”. (Sibila, 2013:267). Así que estos espacios de comunicación e interacción virtual se configuran ideales para la construcción de personajes ficcionales que recrean la realidad a partir de imágenes. 
Como analiza Serrano-Puche (2012), "las peculiaridades del entorno digital potencian la capacidad del usuario de construir y representar un personaje, de presentar su identidad de manera controlada y selectiva, a fin de ofrecer una versión idealizada de sí mismo”. (2012:12).

Así analizan los entrevistados:

Mario: No divulgo las fotografías en las redes sociales. He perdido el sentido de exhibicionismo que en algún momento tuve porque no me gusta ver fotos de otras personas exhibiéndose en las redes. También pienso mucho en mi privacidad, no quiero exponerme. Pero me parece bien cuando la gente lo hace para compartir con amigos o familiares algunos momentos personales, pero considerando que sabe acotar el número de personas que van a mirar las imágenes.

Carmen: Como no me gusta cómo salgo en las fotos, no las divulgo en las redes sociales. Pero me parece bien que las personas divulguen sus imágenes si están guapas, o se sienten bien. No veo ningún problema.

Nuria: Hoy en día mucha gente quiere tener "likes" (en Facebook). Yo no, yo subo las fotos esperando que comenten cosas que tengan a ver con la fotografía. Tampoco me gustan comentarios como "vamos tomar un café" o cosas del estilo.

A la hora de seleccionar lo que va a publicar en Facebook, Nuria afirma que siempre piensa en quién podrá mirar las fotografías.

Por ejemplo, pienso si mi padre va a ver la foto. Además, he subido fotos con personas que después me han pedido para sacarla de la red porque no querían ver sus vidas expuestas en las redes sociales. No publico más fotos si alguna de estas personas aparece.

En la ambigüedad de publicar o no la fotografía, Nuria ha definido un criterio de acción para sus decisiones: "Ahora publico fotos como homenajes a personas que me gustan y que me gusta enseñar momentos que hemos pasado juntos”.

María que afirmó casi nunca publicar fotos en las redes sociales, también considera que algunas cosas son publicables y otras no.

No hay problema si está relacionado a un contexto, a un viaje o cuando estoy con mi hijo haciendo algo específico. Lo que me molesta es que muchas veces se explicitan cosas privadas que no son necesarias, como exposición gratuita. Entonces cuando me hacen una foto sin contexto, no me gusta.

Entre los entrevistados, hay un consenso sobre el tipo de fotografía que se puede publicar en las redes sociales: las fotografías que representan momentos vividos con amigos o familiares, y tienen por tanto un sentido comunitario que autoriza la imagen ser compartida en las redes sociales. El marco de lo que se configura como publicable se contrapone con una tendencia a que muchos han rechazado que es 
la fotografía individual en contextos de rutinas diarias, es decir, fotografías de personas realizando actividades cotidianas han sido catalogadas como exhibicionistas y por esto, no tienen la total aprobación de los entrevistados.

El conjunto de reflexiones planteados a partir de las narraciones de los entrevistados apunta posibilidades para ampliar los estudios sobre la fotografía como medio de representación y presentación social del cuerpo, su relación con la imagen corporal subjetiva y objetiva y las funciones sociales que ejerce. Es evidente que no se presentan conclusiones, sino puntos de partida para hipótesis que deben ser contrastadas entre grupos sociales más específicos, que revelen, como afirma Bourdieu, una relación entre la estructura socioeconómica y los modos de conducta.

Por esto, señalamos la pose y la espontaneidad como las dos caras de un proceso dicotómico en la producción fotográfica de retrato, donde la pose revela la estructura cultural y los modelos de representación (la imagen corporal en el sentido de Mary Douglas) y la foto "espontánea" desea revelar la fachada, el escenario y las maneras (en el sentido de Goffman).

Por otro lado, como sujeto fotografiado, hay una incomodidad con relación a la propia imagen marcada por los modelos de representación ajenos que indican los patrones de belleza y se conforman como censurantes para la producción de autorretratos. Aquí, como hemos visto, el empoderamiento generado por el acceso extendido a las cámaras y a los espacios de visibilidad se queda anulado por la imposición de los modelos de representación que marcan lo que es visible o no, y en algunas ocasiones provocan mecanismos de transformación como es el retoque fotográfico o el uso de filtros.

La transformación de la imagen corporal en una fotografía se ha revelado un desagrado cuando algunos entrevistados afirman no reconocerse en las fotografías y al afirmar que prefieren la imagen del espejo a la de la fotografía. En parte, esto se genera por el uso de la técnica que puede provocar alteraciones de fisionomía. Por otro lado, el reflejo en el espejo es subjetivo, no permite acompañar la transformación de la imagen corporal en las diferentes fachadas usadas por el sujeto en los escenarios de la vida social. Al contrario, la fotografía revela las facetas cambiantes del sujeto, objetivadas. La imagen además tiene su poder anacrónico, que supera la vida mismo del fotografiado permaneciendo como memoria de su vida. En este sentido, la idea de huella puede ser un marco en la relación de la imagen corporal con su representación fotográfica.

Esta sensación rara de mirarse en la fotografía y no reconocerse como tal, nos hace cuestionar la supuesta fidelidad a la realidad, 
otorgada durante tanto tiempo a la fotografía como registro documental. Se percibe de alguna forma la virtualidad que el proceso fotográfico construye sobre el cuerpo al estereotiparlo, sea a través del modo de producción que hace una lectura técnica del cuerpo fotografiado, sea a través de la mirada que hace una lectura estética. Como afirma Castañares, "lo real se nos manifiesta de forma privilegiada en la corporeidad”. (2010: 89).

Por fin, es evidente la relación que se configura entre la imagen corporal y los derechos relacionados a la intimidad que están determinados constitucionalmente a través del derecho de imagen. De acuerdo con algunas narrativas, el uso de las fotografías de retrato y autorretrato en las redes sociales revela inquietudes sobre la privacidad y generan conflictos entre lo que es o debe ser público y privado. La vigilancia y el espectáculo (Le Breton, 2002:193) marcan la experiencia del cuerpo como imagen visible y observada, caracterizando esta dualidad entre el público/privado para cada sujeto. Esta ambigüedad implica una incesante interpretación de la vida social, que muchas veces es elaborada a partir de simulacros (Baudrillard, 2007).

\section{REFERENCIAS}

Aguado, José Carlos. Cuerpo humano e imagen corporal. México: Universidad Autónoma de México, 2004.

Ardévol, Elizenda y Gomez-cruz, Carlos. "Cuerpo privado, imagen pública:el autorretrato en la práctica de la fotografía digital” en Revista de Dialectología y Tradiciones Populares, 1, 2012, pp.181-208. Disponible en: http://dialnet.unirioja.es/servlet/articulo?codigo=4019176

Barthes, Roland. La cámara lúcida. Nota sobre la fotografía. Barcelona: Editora Paidós, 1989.

—. "The Photographic Message". En S. Sontag (ed.), A Barthes Reader, Hill and Wang, 1982, pp.194-210

Baudrillard, Jean. Cultura y Simulacro. Barcelona: Ed. Kairós, 2007.

—. La Sociedad de Consumo. México: Siglo xxi, 1970.

Bourdieu, Pierre. Un Arte Medio. Ensayo Sobre los Usos Sociales de la Fotografía. Barcelona: Editorial Gustavo Gili, SA, 2003.

Buxó, Ma Jesus. “... que mil palabras”. En De la Investigación Audiovisual. Fotografía, Cine, Vídeo, Televisión. M. a Jesús Buxó y Jesús M. De Miguel (eds.). Proyecto A Ediciones. Barcelona, 1999.

Casajús, C. Anales de Historia del Arte, 19, Universidad Complutense de Madrid, 2009 Disponible en: https://revistas.ucm.es/index.php/ ANHA/article/viewFile/ANHA0909110237A/30871 


\section{LA IMAGEN CORPORAL COMO RELACIÓN SOCIAL}

Castañares, Wenceslao. "El uso de la fotografía en la autorrepresentación de los sujetos en las redes sociales". En Imaginar la realidad. Ensayos sobre la representación de la realidad en el cine, la televisión y los nuevos medios. Sevilla-Zamora: Comunicación Social (2010): 69-90.

D’Angelo, Ana “La Experiencia de la corporalidad en imágenes. Percepción del Mundo, producción de sentidos y subjetividad" Tabula Rasa, Bogotá, 13 (2011), pp.235-251 http://www.revistatabularasa.org/ numero-13/09dangelo.pdf

Douglas, Mary. Implicit Meanings. Selected essays in Anthropology, Routledge, London, 2003b.

Goffman, Erving. La presentación de la persona en la vida cotidiana. Buenos Aires: Amorrortu, 2006.

Gonzélez, Carolina. “Identidad y Percepción Social del Cuerpo”. En T. Porzecanski (comp.) El Cuerpo y Sus Espejos. Planeta, 2015, pp. 17-29 Disponible en: http://ceip.edu.uy/IFS/documentos/2015/sexual/cu rsos/jornada2/identidad-y-percepcion-social-del-cuerpo-el-cuerpo-y-sus-espejos.pdf

Guerrero, Joaquín. "Perspectivas socioculturales sobre el cuerpo: del esquema evolucionista a la teoría del estigma de E. Goffman”. En La Razón Histórica, 22, 2013, pp.136-170.

Heidt, Erhard. "Cuerpo y cultura: la construcción social del cuerpo humano" en La Certeza Vulnerable, cuerpo y fotografía en el siglo XXI. Barcelona, Editora Gustavo Gili, 2004.

Le Breton, David. Antropología del Cuerpo y modernidad. Buenos Aires: Nueva Visión, 2002.

Kossoy, Boris. Lo efímero y lo perpetuo en la imagen fotográfica. Madrid: Ediciones Cátedra, 2014.

Machado, Arlindo. “A fotografia como expressão do conceito”. En Studium, 2, unicamp, 2000. Disponible en: http://www.studium.iar.unicamp. br/dois/

Martí, Josep. "La Presentación Social del Cuerpo: Apuntes Teóricos y Propuestas de Análisis". En Desvelando el cuerpo, perspectivas desde las ciencias sociales y humanas. Editorial Alta Fulla, 2010., pp. 107-121 Disponible en: http://digital.csic.es/handle/10261/38271

—. "Presentación social del cuerpo, postcolonialidad y discursos sobre la modernidad". En Revista Latinoamericana de Estudios sobre Cuerpos, Emociones y Sociedad. No10. Año 4. Diciembre 2012-marzo de 2013. Argentina. ISSN: 1852-8759. pp. 80-92.Disponible en http:// digital.csic.es/bitstream/10261/82419/1/JosepMarti-2012-Presentación\%20social\%20del\%20cuerpo.....pdf

Mirzoeff, Nicholas. Una introducción a la cultura visual. Barcelona: Paidós, 2003. 
Moreira, M. "La representación de indígenas y afrodescendientes en la fotografía antropológica en Brasil”. En Fotocinema. Revista cientifica de Cine y Fotografía, n. ${ }^{\circ} 22$, enero de 2021, pp. 279-04, doi:10.24310/ Fotocinema.2021.vi22.11722.

Pultz, John. La fotografía y el cuerpo. Madrid: Akal, 2003.

RAIch, Llorenç. Corpografía. El cuerpo en la fotografía contemporánea. Madrid: Casimiro, 2012.

Ribalta, Jorge. Archivo Universal. La condición del documento y la utopía fotográfica moderna. Guía Exposición Museu d'Art Contemporani de Barcelona, 2008.

SÁncheZ-Moreno, Iván. "La irreal realidad de lo visto (y previsto). Construcción fotográfica de la identidad y subjetividad en el siglo xix". En Quaderns-E, 16 (1-2), pp. 116-132 Disponible en: http://www. antropologia.cat/files/Quaderns-e16(1-2)_Sanchez.pdf

Schilder, Paul. Imagen y apariencia del cuerpo humano: estudios sobre las energías constructivas de la psique. Barcelona: Paidós, 1983.

Serrano Puche, Javier. "La presentación de la persona en las redes sociales: una aproximación desde la obra de Erving Goffman”. En Anàlisi, 2012, 46, 1-17 https://dadun.unav.edu/handle/10171/27407

Paula, Sibilia. La Intimidad Como Espectáculo (Sociologia). Spanish Edition. Fondo de Cultura Económica, 2009.

Sontag, Susan y Gardini Carlos; D’Angelo. Sobre La Fotografía (Contemporánea). Spanish Edition. 001 ed., Debolsillo, 2018.

Este artículo se publica bajo una licencia de Creative Commons Reconocimiento-NoComercial 4.0 Internacional, y puede ser usados gratuitamente para fines no comerciales, dando los créditos a los autores y a la revista. 